\title{
Recent Development of Aptasensor for Influenza Virus Detection
}

\author{
Soo Min Kim ${ }^{\dagger}$, Jinmyeong Kim ${ }^{\dagger}$, Seungwoo Noh, Hiesang Sohn \& Taek Lee iD*
}

Received: 25 July, 2020 / Accepted: 22 September, 2020 / Published online: 16 November, 2020

(C) The Korean BioChip Society and Springer 2020

\begin{abstract}
In nowadays, we have entered the new era of pandemics and the significance of virus detection deeply impacts human society. Viruses with genetic mutations are reported nearly every year, and people have prepared tools to detect the virus and vaccines to ensure proper treatments. Influenza virus (IV) is one of the most harmful viruses reporting various mutations, sub-types, and rapid infection speed for humans and animals including swine and poultry. Moreover, IV infection presents several harmful symptoms including cough, fever, diarrhea, chills, even causing death. To reduce the IV-induced harm, its proper and rapid detection is highly required. Conventional techniques were used against various IV sub-types including H1N1, H3N2, and H5N1. However, some of the techniques are time-consuming, expensive, or labor-intensive for detecting IV. Recently, the nucleic acid-based aptamer has gained attention as a novel bioprobe for constructing a biosensor. In this review, the authors discuss the recent progress in aptasensors for detecting IV in terms of an electrochemical and an optical biosensor.
\end{abstract}

Keywords: Influenza virus, Aptamer, Electrochemical, Optical, Biosensor

\section{Introduction}

Globalization leads to economic growth in intercontinental commerce. People typically believe that glo-

Department of Chemical Engineering, Kwangwoon University, 20 Kwangwoon-ro, Nowon-gu, Seoul 01899, Republic of Korea

These authors contributed equally.

*Correspondence and requests for materials should be addressed to

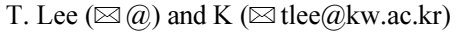

balization simultaneously provided prosperity to develop as well as developing countries. Human interactions between countries bring about explosive growth in the tourism industry that boosts the economic growth of many countries. However, though globalization brings about economic growth, it also leads to new rises in various infectious diseases and pathogenic viral agents like severe acute respiratory syndrome coronavirus (SARS-CoV) ${ }^{1,2}$, Middle East respiratory syndrome coronavirus (MERS-CoV) ${ }^{3}$, coronavirus disease 2019 (COVID-19) ${ }^{4,5}$, Zika virus $^{6.7}$, and others ${ }^{8-10}$.

Among them, influenza virus (IV) is extremely important in that it usually infects the host, causing the "flu" and presents with several symptoms including cough, high fever, diarrhea, and sore throat ${ }^{11,12}$. IV undergoes several mutations and easily infects humans, swine, birds, and bats almost every year ${ }^{13-15}$. Each different infected species of a host can infect other specie hosts, enabling human-to-animal spread and vice versa. Phylogenetically, IV is classified as a single-stranded negative-sense RNA, and can be divided into four types including influenza A (IAV), B (IBV), C (ICV), and D (IDV) ${ }^{16,17}$. The virus can be classified into highly pathogenic influenza (HPI) and low pathogenic influenza (LPI) based on the infectious ability. Among them, influenza A virus is highly infectious and causes economic, health, and ethnic problems.

Influenza A viruses genetically encode for several proteins such as polymerase, hemagglutinin (HA), nucleoprotein, neuraminidase (NA), membrane proteins, and non-structural proteins. Especially, the envelope proteins, HA and NA, can be used to determine the influenza A virus subtype ${ }^{18}$. HA is an antigenic glycoprotein found on the surface of the IV that 
help the binding of IV to sialic acid residues on the surface of the epithelial cells of organisms. So far, sixteen types of HA proteins have reported in the IAV, IBV, ICV and IDV. NA found on the surface of IV that mediated the virus binding to the cell to be released from the host cell. NA acted as the cleavage of sialic acid groups from glycoproteins. And, nine types of NA proteins have reported in the IAV, IBV, ICV and IDV. Among them, eight types of IV HA proteins $(\mathrm{H} 1, \mathrm{H} 2, \mathrm{H} 3, \mathrm{H} 5, \mathrm{H} 6, \mathrm{H} 7, \mathrm{H} 9$, and $\mathrm{H} 10)$ can infect humans and cause several pandemics ${ }^{19,20}$.

For example, the outbreak of IV H1N1 resulted in the Spanish flu in 1918 that had between 50 and 100 million victims ${ }^{21}$. In 1968, IAV H3N2 infected 500,000 victims in the Hong Kong area ${ }^{22}$. More recently, the 2009 swine flu pandemic was cause by H1N1, and around 400,000 people were victimized ${ }^{23}$. Moreover, avian influenza H5N1 can also infect people, making thousands of victims and economic damage in many countries ${ }^{24}$.

Conventionally, there are two types of methods have been used to detect IV. Immunosensors like the enzyme-linked immunosorbent assay (ELISA) and genetic biosensor including the reverse transcriptase polymerase chain reaction (RT-PCR) method were widely used ${ }^{25-28}$. The antibody-based ELISA technique provided high accuracy and generality. Based on antigen-antibody recognition, the ELISA technique is regarded as a general detection tool for IAV surface antigen detection ${ }^{29}$. However, it required large amounts of expensive antibodies, a long detection time, and a well-trained researcher. In the case of RT-PCR, this technique provides more sensitivity and selectivity compared to ELISA, and it can determine the genetic information. However, the PCR-based method requires an extra purification step and expensive analytical devices for detecting $\mathrm{IV}^{27,29,30}$.

Today, aptamer-based detection methods have been suggested to overcome these current problems including expensive antibody production cost, ethnical problem, fast manufacturing $\cos ^{31,32}$. The aptamer is composed of several nucleic acid or peptide sequences that can bind with high affinity to specific targets like proteins, small molecules, chemicals, and nucleic acids ${ }^{33}$. These non-canonical nucleic acids and peptides have been applied to therapeutic agents in pharmaceutical science ${ }^{34}$ and detection elements for various biosensors ${ }^{35}$.

The early stage of aptamer research was reported by Tuerk, Gold, Ellington, and Szostak through in vitro systematic evolution of ligands by exponential enrichment $\left(\right.$ SELEX) ${ }^{36}$. Consequently, several meth- ods were developed to obtain RNA or DNA aptamers $^{37}$. Recently, the cell-based in vivo selection method $^{38}$ and graphene-based selection method ${ }^{39}$ were reported. When the target binds to the aptamer, the 3D ligand structure between target and aptamer flexibly changes to form a thermodynamically stable structure $^{40}$. Aptamers have been studied since 1980 to find several aptamers for understanding the binding mechanism at a molecular level, treating the intractable disease, and detecting the specific target using aptamer-target interaction ${ }^{41,42}$. Aptamers have several advantages compared to antibodies: 1) cheap production cost, 2) small molecular size, 3) easy-to-tailor for functionalization, 4) ability to tune binding affinity, 5) the ability to chemically synthesize, and 6) fast manufacturing speed $^{43}$ (Table 1).

Based on these advantages, several groups tried to fabricate a biosensor to detect cancers ${ }^{44}$, bacteria $^{45}$, small molecules ${ }^{46}$, diseases ${ }^{47}$ and viruses ${ }^{48}$. In particular, detecting highly infectious viruses requires fast manufacturing speed and high throughput screening ${ }^{49}$. The chemically synthesized aptamer can be a powerful agent for constructing a virus biosensor ${ }^{50}$. Thus, aptasensor fabrication can lead to IV biosensor development. In this review, we briefly discuss the recent trends in aptasensor for detecting IV virus using an optical method widely used in the field and an electrochemical method that is advantageous in miniaturization, portability, easy-to-handle it, user-friendly interface and has a very high sensitivity ${ }^{51}$.

\section{Electrochemical-based Aptasensor for IV Detection}

In virus detection, diagnostic tools need to be accurate, fast, and specific. To ensure wide use and mass production, it must be easy-to-use and low-cost ${ }^{51}$. In light of these aspects, electrochemical detection methods are very attractive tools for virus detection. Electrochemical biosensors require fewer samples and are highly sensitive. In addition, it is easy to downsize the device, and it can be manufactured at a low $\operatorname{cost}^{52}$. Due to the above-mentioned advantages, research on the electrochemical biosensor using an aptamer has been actively conducted ${ }^{51}$. A typical electrochemical aptasensor research method screens aptamers using SELEX and selects aptamers with a low dissociation constant $\left(\mathrm{K}_{\mathrm{D}}\right)$ among the proposed aptamer candidates. The selected aptamer is immobilized on a substrate to bind with the target virus. At this stage, according to the type of transducer, it is 
Table 1. Comparison between aptamer and antibody for IV detection biosensor construction.

\begin{tabular}{|c|c|c|}
\hline & Aptamer & Antibody \\
\hline $\begin{array}{c}\text { Manufacture of } \\
\text { Bioprobe }\end{array}$ & Chemical Synthesis & $\int_{0} A$ \\
\hline Stability & $\begin{array}{l}\text { Less than } \\
\text { Antibody }\end{array}$ & Stable \\
\hline Production Time & $\sim 8$ weeks & $\sim 6$ months \\
\hline $\begin{array}{l}\text { Modification } \\
\text { For Biosensor } \\
\text { Fabrication }\end{array}$ & $\begin{array}{l}\text { Easy to modification } \\
\text { Signal reporter, linker, receptor }\end{array}$ & Difficult to chemical modification \\
\hline Bioprobe Size & Small (<30 KDa) & Large ( 150 KDa) \\
\hline
\end{tabular}

analyzed by checking the signal change using amperometric $^{53}$, voltammetric ${ }^{54}$, potentiometric ${ }^{55}$, or impedimetric methods ${ }^{56}$.

Notably, Bhardwaj's group conducted SELEX using recombinant influenza A mini-HA protein, and eleven aptamer sequences were obtained as a result ${ }^{57}$. $\mathrm{K}_{\mathrm{D}}$ values were determined for each aptamer sequence using qPCR. It was confirmed that V46 and V57 showed low $K_{D}$ values of $19.2 \mathrm{nM}$ and $29.6 \mathrm{nM}$, and they showed affinities similar to antibodies. Thereafter, ITO glass was immersed in a solution containing $\mathrm{NH}_{4} \mathrm{OH}, \mathrm{H}_{2} \mathrm{O}_{2}$, and $\mathrm{H}_{2} \mathrm{O}$ at $60^{\circ} \mathrm{C}$ to form a hydroxyl group on the surface. The modified ITO was reacted with $1 \%$ polyethylenimine (PEI) solution for two hours and before incubating with a negatively charged V46 aptamer. To remove the physically adsorbed aptamer, it was immersed in ultrapure water and treated with $1 \%$ BSA solution to block the surface activation site (Figure 1(A)). Figure 1(B) shows that the fabricated aptasensor was subjected to cyclic voltammetry $(\mathrm{CV})$ and differential pulse voltammetry (DPV) in $1 \mathrm{X}$ PBS $(\mathrm{pH}$ 7) containing $5 \mathrm{mM}$ $\left[\mathrm{Fe}(\mathrm{CN})_{6}\right]^{3-/ 4-}$ and $0.5 \mathrm{M} \mathrm{KCl}$. CV was performed to test the binding affinity of the V46 and V57 aptamers, and the limit of detection (LOD) of the aptasensor was determined using DPV. As a result, the LOD of the produced aptasensor was $3.7 \mathrm{PFU} / \mathrm{mL}$ and it showed high reproducibility (Figure 1(D)). In addition, it showed high selectivity by reacting with H1N1 subtypes and not with other influenza viruses (Figure 1(C)).

Meanwhile, research into improving the performance of an electrochemical biosensor using nanomaterials is actively being conducted ${ }^{58-60}$. The specific surface area was increased by insituating the nanomaterial to the substrate surface. The bioprobe immobilized to the surface increases the chance of recognizing analyte and increases the intensity of the redox current, thus increasing sensitivity. In addition, carbon nanotubes, graphene, and gold nanomaterials, which are used in electrochemical biosensors, have excellent electrical properties ${ }^{61}$.

An example of improving the performance of an electrochemical sensor using nanomaterials is a recently reported study by Lee's group ${ }^{54}$. Figure 2(A) shows a schematic image of this study. The aptamer sequence that selectively binds the HA protein of H5N1, the DNAzyme sequence that generates an 
A
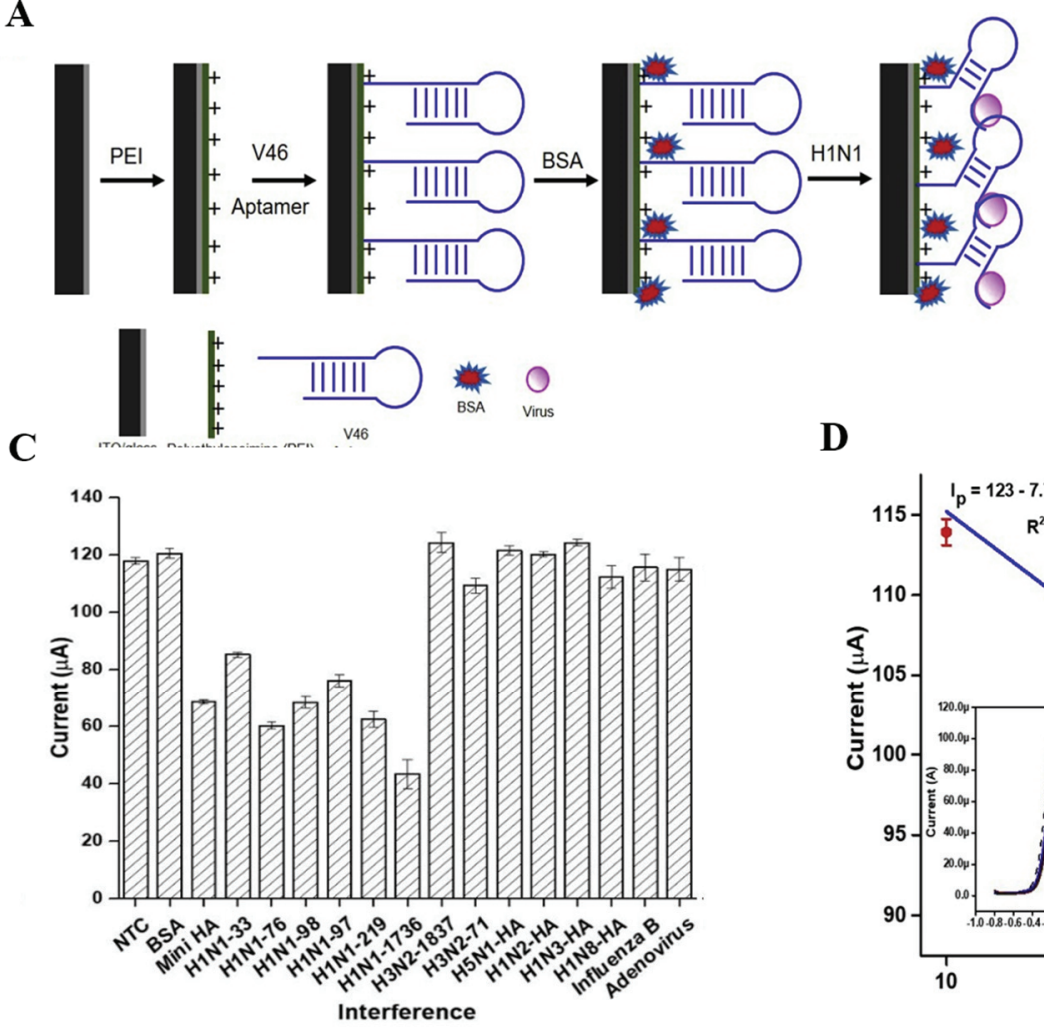

B

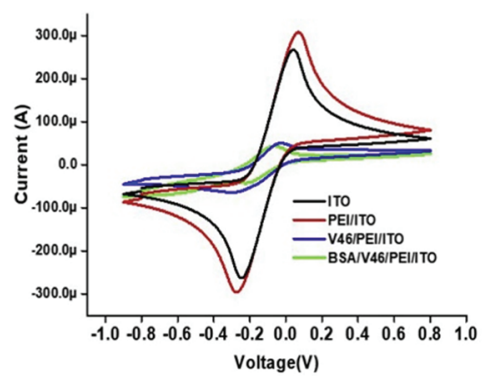

D

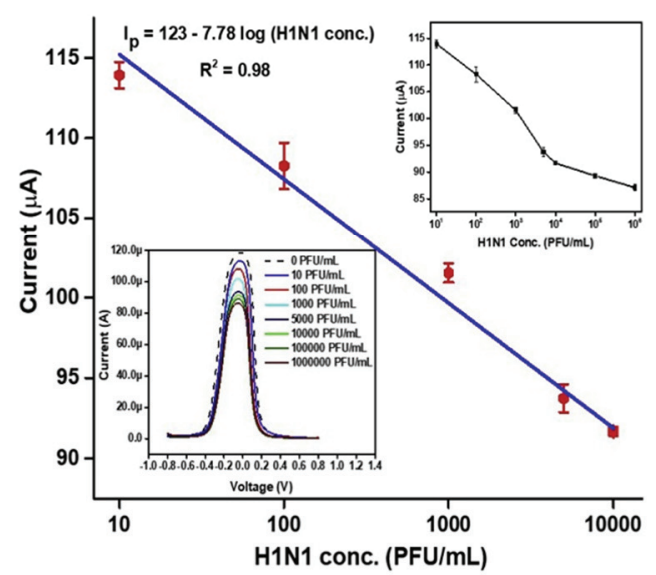

Figure 1. Aptasensor fabrication. (A) Aptasensor fabrication process. (B) Cyclic voltammogram fabrication step. (C) Qualitative specificity of aptamer V46 against several H1N1 subtypes. (D) Linear calibration curve in various H1N1 concentrations $\left(10^{1}-10^{4}\right.$ PFU) (Reproduced with permission from [79], published by Elsevier, 2019).

electrochemical signal, and the sequence containing the thiol group so that it can be immobilized on the substrate, are composed of a 3 way junction (DNA $3 \mathrm{WJ}$ ) and used as a bio probe. The signal was amplified using porous gold nanoparticles (pAuNP) with a diameter of 60-110 nm. Figure 2(B) showed the schematic diagram of DNA $3 \mathrm{WJ}$ and the results of TBM-PAGE performed to confirm that DNA $3 \mathrm{WJ}$ was correctly formed. Cysteamine, pAuNP, and DNA $3 \mathrm{WJ}$ were applied to the prepared electrode, immobilized using a self-assembly method, and treated with $1 \mathrm{mM}$ hemin. The hemin molecule has a single guanine sequence of the DNAzyme sequence, a Gquadruplex DNA structure, and activity similar to peroxidase. The fabrication process was confirmed using an atomic force microscope (AFM) and CV, and the electrode immobilized with pAuNP was confirmed to have higher electrical activity than the bare electrode. The performance of the sensor was confirmed by CV and had a linear range of $1 \mathrm{pM}$ to 100 nM HA protein. The limit of detection was determined at $1 \mathrm{pM}$ in chicken serum (Figure 2(C)). This study was conducted in chicken serum and is ex- pected to be used in the field because it is label-free.

So far, we have examined the influenza virus detection method using amperometric and voltammetric methods. In addition, impedicmetric methods are also widely used to measure the change in charge transfer resistance $\left(\mathrm{R}_{\mathrm{ct}}\right)$ as a biorecognition event occurs on the working electrode surface. In the study by Bai's group, influenza virus H1N1 was detected using the impedimetric method described above ${ }^{62}$. After selecting a candidate aptamer using SELEX, $\mathrm{K}_{\mathrm{D}}$ was determined by using an enzyme-linked oligonucleotide assay (ELONA) method, and LOD was confirmed. As a result, experiments were conducted using A20S and A8S8 with the lowest $\mathrm{K}_{\mathrm{D}}$, and the LOD of direct ELONA were $2 \mathrm{ng} / \mu \mathrm{L}$ and $0.3 \mathrm{ng} / \mu \mathrm{L}$. Next, an electrochemical impedance spectroscopy (EIS) aptasensor was fabricated. After polishing the gold electrode, $\mathrm{CV}$ was performed at a rate of $0.1 \mathrm{~V} / \mathrm{s}$ between -0.2 and $1.2 \mathrm{~V}$ in $0.5 \mathrm{M} \mathrm{H}_{2} \mathrm{SO}_{4}$. The HS-A20S solution was mixed with $100 \mathrm{mM}$ TCEP to incubate the gold electrode for $12 \mathrm{~h}$. It was washed with PBS, incubated in $1 \mathrm{mM} \mathrm{MCH}$ aqueous solution for $4 \mathrm{~h}$, and washed three times with PBS. The manufacturing 
A

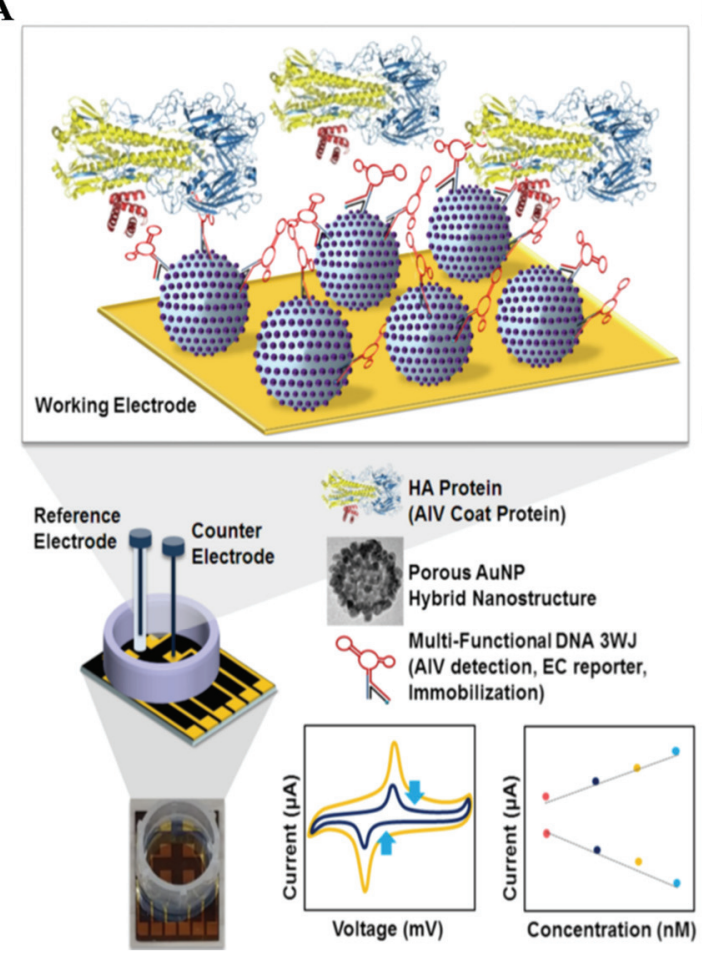

B
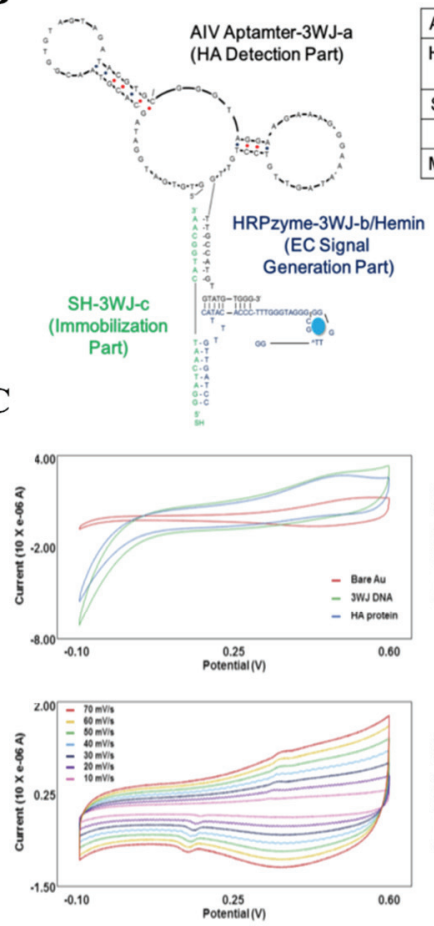
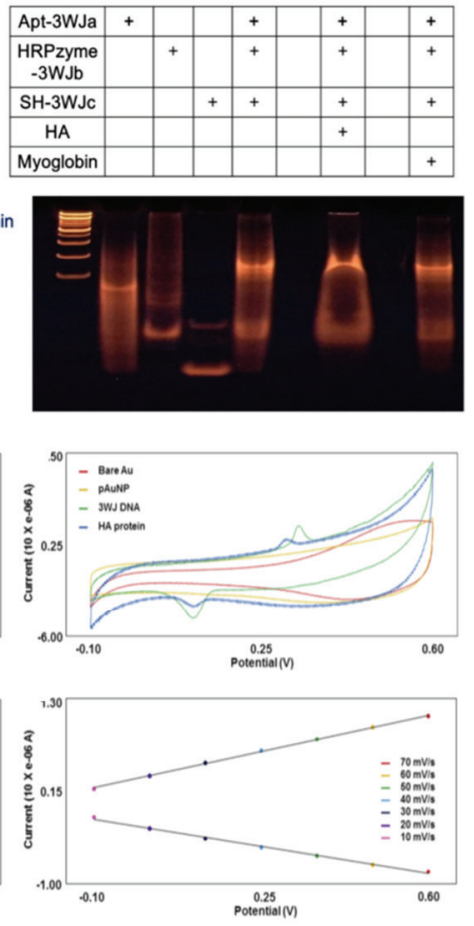

Figure 2. (A) Schematic and photo image of aptasensor. (B) Schematic diagram of DNA structure and TBM PAGE results of DNA 3WJ. (C) Cyclic voltammogram of HA protein's various concentration (Reproduced with permission from [76], published by Elsevier, 2019).

steps were confirmed through EIS. EIS was measured in PBS containing $1 \mathrm{M} \mathrm{NaCl}, 5 \mathrm{mM} \mathrm{K}_{3} \mathrm{Fe}(\mathrm{CN})_{6}$, and $5 \mathrm{mM} \mathrm{K}_{4} \mathrm{Fe}(\mathrm{CN})_{6}$. The frequency range was $0.03 \mathrm{~Hz}$ to $200 \mathrm{kHz}$, and the amplitude was $10 \mathrm{mV}$. As a result, both increases and decreases in $R_{c t}$ were observed when the biorecognition event of the target and aptamer occurred, and the researchers explained these using two mechanisms. As the first factor, $\mathrm{R}_{\mathrm{ct}}$ increases because the aptamer does not fold upon non-specific binding of the target and the aptamer. Conversely, the aptamer folds upon specific binding with the target, resulting in more space for electron transport. Therefore, $\mathrm{R}_{\mathrm{ct}}$ decreases. The above-mentioned hypothesis was verified using a B virus with low affinity and H1N1 with high affinity (Figure 3(A), (B)). As a result, the LOD of the EIS aptasensor was improved by approximately 300 times compared to the ELONA method, which was $0.9 \mathrm{pg} / \mu \mathrm{L}$. Figure 3 (C) shows the selectivity test of this sensor. It was confirmed that the signal decreased when binding with H1N1, but it increased when binding to other substances.

A method of using an interdigitated electrode (IDE) to increase the impedance signal is also frequently used. The IDE is an electrode designed to engage two or more electrodes. It has a high signal/noise ratio because it maximizes the impedance change on the surface, reduces the detection time, and minimizes the interference effect of non-target analytes in solution. Furthermore, it is compact compared to other electrode systems and has advantages like fast establishment of steady state $^{63}$. Figure 4(A) shows an example of the IDE structure. The equivalent circuit when using the IDE of the above structure and the Nyquist plot before and after detection are shown in Figure 4(B). Fu's group detected H5N1 using an enzyme catalyst, gold nanoparticles, and an $\mathrm{IDE}^{64}$. Nanocomposites were formed by coating magnetic beads (MB) with specific aptamers on $\mathrm{H} 5 \mathrm{~N} 1$ and combining concanavalin A (ConA), glucose oxidase (GOx), and gold nanoparticles. The generated complex of aptamer-coated MB, H5N1, and enzymenanocomposite were incubated to form a sandwich complex. Next, it was transferred to a glucose solution to induce an enzymatic reaction to generate gluconic acid and ionize to increase the ionic strength of the solution, thereby reducing the impedance of the IDE. This method was confirmed to have a LOD of $8 \times 10^{-4}$ HAU (Hemagglutinin Unit) in a $200 \mu \mathrm{L}$ sample using high enzyme catalyst efficiency and high 

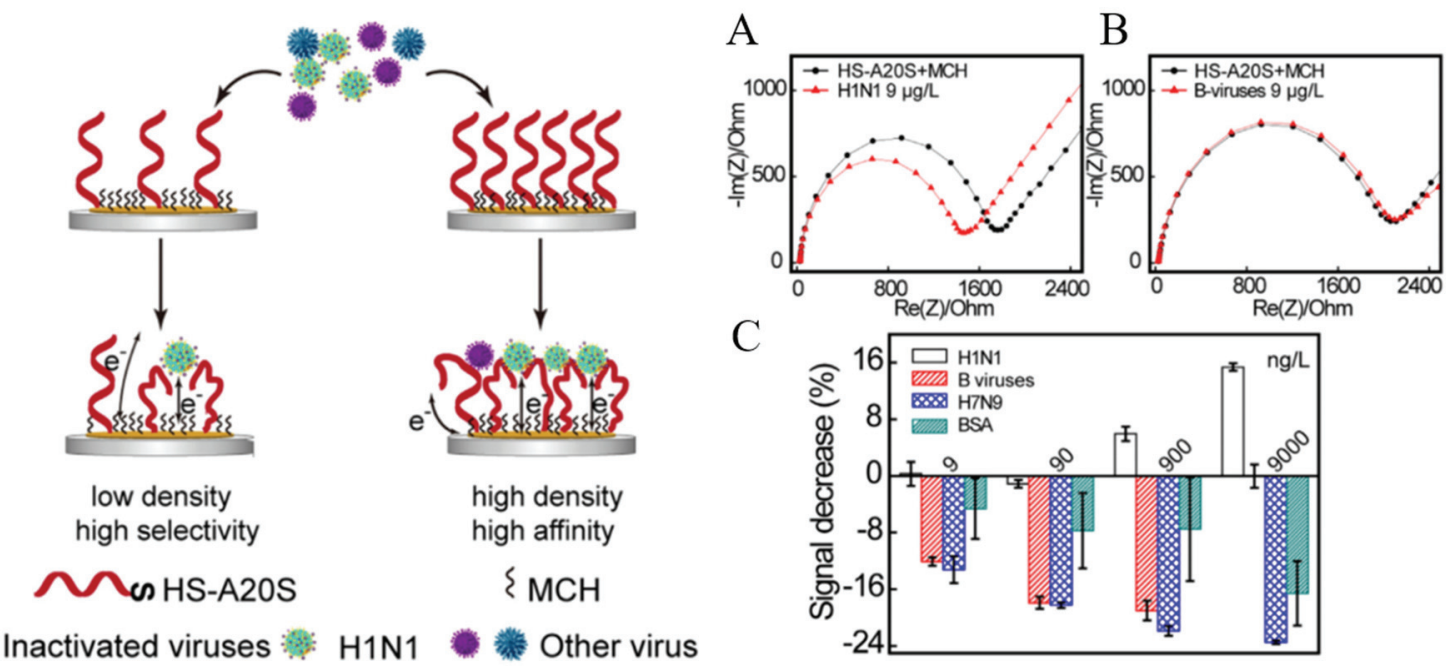

Figure 3. Schematic illustration of detection process. (A) Nyquist plots of the sensor against H1N1 (B) and B viruses. (C) Selectivity of this sensor (Reproduced with permission from [84], published by Elsevier, 2018).

A
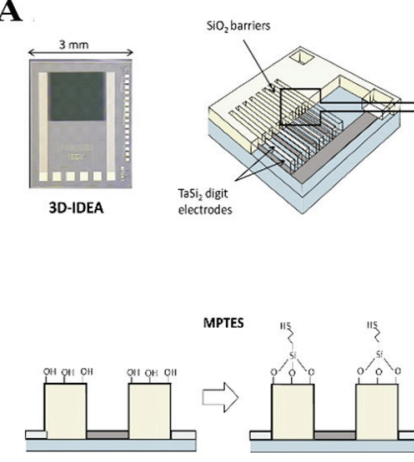
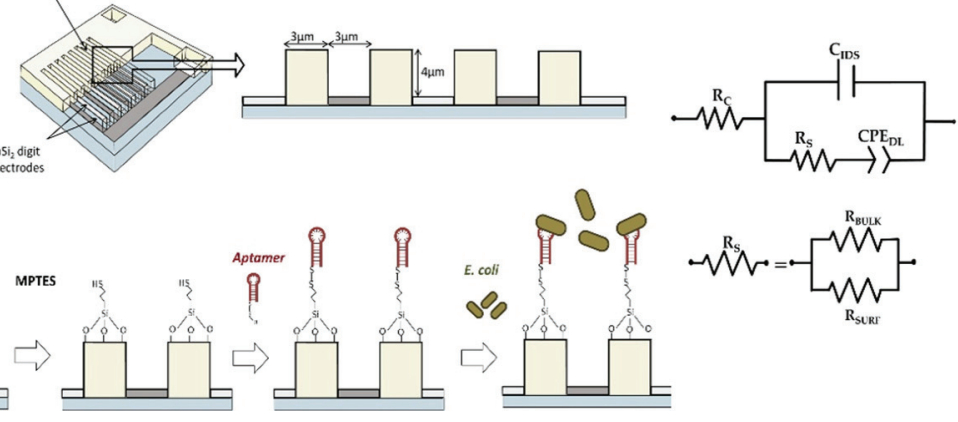

B

Figure 4. (A) Schematic illustration of used IDE and fabrication process. (B) Electrical equivalent circuit and Nyquist plot used for impedance spectra fitting (Reproduced with permission from [85], published by Elsevier, 2018).

sensitivity of electrochemical impedance to ionic strength. Since this method is flexible, it is expected to be widely used. Table 2 showed the electrochemical biosensing techniques for IV detection, which showed the target and LOD.

\section{Optical-based Aptasensor for IV Detection}

Optical biosensors are powerful tools to detect small molecules and real-time analytes with high sensitivity, and are low-cost analytical methods ${ }^{68,69}$. The optical biosensor works by measuring the interaction between the analyte and the probe by measuring changes in optical properties like light absorption, reflection, and emission. In addition, the discovery of nanoparticles has led to signal amplification due to the optical properties of nanoparticles, resulting in more precise biosensor development ${ }^{70}$. Detection methods like fluorescence ${ }^{71}$, colorimetric ${ }^{72}$, surface plasmon resonance ${ }^{73}$, and Raman spectroscopy ${ }^{74}$ are mainly used as optical biosensor methods for detecting viruses.

Fluorescent biosensors are useful for real-time detection, and they achieve a million-time higher sensitivity and faster response than absorption by labeling the analyte or probe in advance. The fluorescent biosensor uses a fluorescent dye like a quantum dot (QD) to detect the target material by increasing or decreasing the fluorescent signal. Xu's group labeled a QD for fluorescence signal at the DNA 3 '-end, which is a sequence complementary to the aptamer to detect 
Table 2. The electrochemical biosensing techniques discussed in this review.

\begin{tabular}{lllll}
\hline Bioprobe & Detection Method & Detection Limit & Target & Ref \\
\hline Aptamer & DPV & $3.7 \mathrm{PFU} / \mathrm{mL}$ & H1N1 HA protein & {$[57]$} \\
Aptamer & CV & $1 \mathrm{pM}$ & H5N1 HA protein & {$[54]$} \\
Aptamer & EIS & $0.9 \mathrm{pg} / \mu \mathrm{L}$ & H1N1 Particles & {$[62]$} \\
Aptamer & Impedimetric & $8 \times 10^{-4} \mathrm{HAU}$ & H5N1 Virus & {$[64]$} \\
Aptamer & Impedimetric & - & H1N1 Particles & {$[56]$} \\
Aptamer & DPV & $4.3 \times 10^{-13} \mathrm{M}$ & H5N1 Specific sequence & {$[65]$} \\
Aptamer & DPV & $100 \mathrm{fM}$ & H5N1 HA protein & {$[66]$} \\
Aptamer & Amperometric & $0.75 \mathrm{pM}$ & H7N9 cDNA & {$[67]$} \\
\hline
\end{tabular}

avian influenza H5N1. The fluorescence signal is quenched when there is no target substance, but it increases after binding to the target ${ }^{75}$. Hemagglutination unit (HAU) has a detection limit of 0.4 and a detection range of $2^{-1.2}$ to $26 / \mathrm{HAU} 20 \mathrm{ul}^{-1}$. Pang's group developed a method to effectively amplify the fluorescence signal and detect the influenza virus without the fluorescent dye label ${ }^{76}$. It is used to bind the aptamer to $\mathrm{Ag}_{2} \mathrm{SiO}_{2}$ particles and form a G-quadruplex structure when the aptamer is combined with a target. The thiazole orange molecule floating freely in solution hardly exhibits fluorescence, but the G-quadruplex structure acts as a ligand and binds. The metal-enhanced fluorescence effect by nanoparticles shows a strong fluorescence signal. It was confirmed that the developed MEF sensor had a detection limit of rHA in buffer and $3.5 \mathrm{ng} / \mathrm{mL}$ in human serum.

The surface plasmon resonance biosensor utilizes the resonance phenomenon of the surface plasmon wave that occurs when light energy is absorbed from the surface of a conductive material ${ }^{77}$. Among them, a phenomenon in which local vibration occurs on the surface of a metal nanoparticle having a local surface is called a local surface plasmon resonance phenomenon (LSPR). Lee's group developed an LSPR biosensor capable of detecting avian influenza (AIV H4N1) by making a DNA $3 \mathrm{WJ}$ using the multi-functional aptamer ${ }^{78}$. A schematic diagram is shown in Figure 5(A). The researchers fabricated a DNA $3 \mathrm{WJ}$ structure instead of using single-stranded DNA as a probe to detect $\mathrm{H} 5 \mathrm{~N} 1$. The assembled DNA $3 \mathrm{WJ}$ can function as a multifunctional probe capable of performing three functions through functionalization of each strand. The fabricated DNA 3 WJ has an aptamer capable of binding influenza HA, a FAM dye, and a thiol group for signal amplification and surface immobilization. Selective binding of a DNA $3 \mathrm{WJ}$ to influenza HA was confirmed using TBM PAGE gel results in Figure 5(B). In addition, hollow Au spike- like nanoparticles were used to create the LSPR effect. The produced LSPR biosensor performance test results are shown in Figure 5(C). Performance was first tested with various concentrations of HA protein in PBS buffer and before testing in chicken serum diluted 10-fold. Both experiments confirmed the linear relationship between HA protein and LSPR intensity, and each LOD was confirmed to be $1 \mathrm{pM}$. In addition, an increase in the LSPR intensity for the HA protein was evident in the selectivity experiment, and there was little increase in the LSPR intensity between the negative controls.

Since most of the aptamers for detecting influenza target a specific protein HA, there were no aptamers that simultaneously bind to different sites. In other words, little research has been done on aptamerbased sandwich-type virus sensors. Kim's group recently developed immobilization-free SELEX and developed lateral flow strips that detect entire $\mathrm{H} 5 \mathrm{~N} 2$ virus particles using a pair of aptamers capable of binding to target molecules in a sandwich manner ${ }^{79}$. Figure 6(A) shows the graphene-oxide based immobilization-free screening method for developing an ssDNA aptamer capable of binding to the avian influenza virus particle. Figure 6(B) shows the GO-FRET assays for aptamer characterization. GO-SELEX without immobilization is a method in which GO is adsorbed to ssDNA labeled with FAM through $\pi-\pi$ stacking. ssDNA capable of binding to target molecules can be separated from GO due to structural changes. The released aptamers showed fluorescence, and the adsorbed aptamers were quenched by GO. As a result, aptamers that specifically bind only to avian virus particles were characterized. A schematic diagram of the aptamer-based sandwich side flow strip biosensor was developed as shown in Figure 6(C). In addition, actual experimental results are shown according to various concentrations (from left to right: $0,1.5 \times 10^{5}$, $3 \times 10^{5}, 6 \times 10^{5}, 1.2 \times 10^{6}, 2.5 \times 10^{6}, 5 \times 10^{6}, 1 \times 10^{7}$ 
A

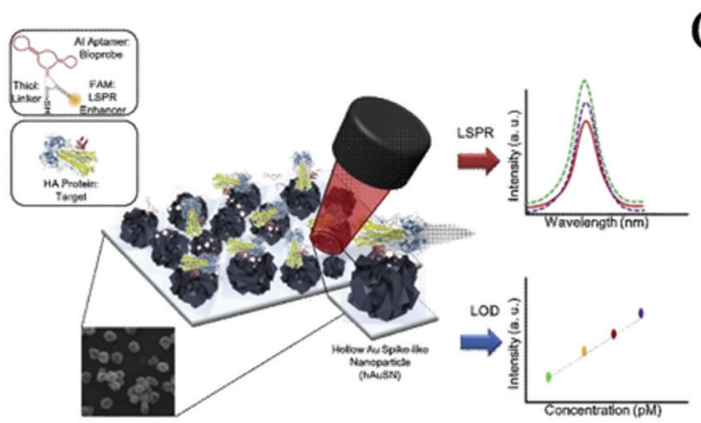

B

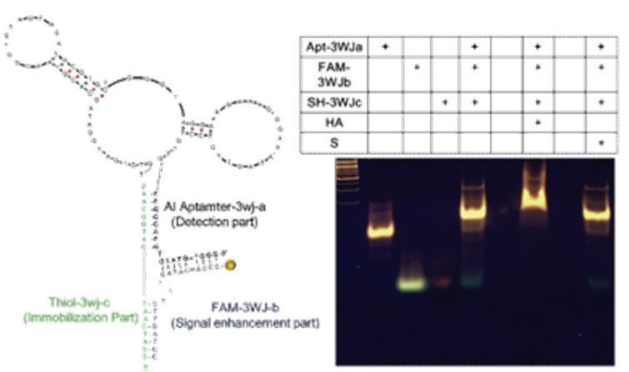

$\mathrm{C}$
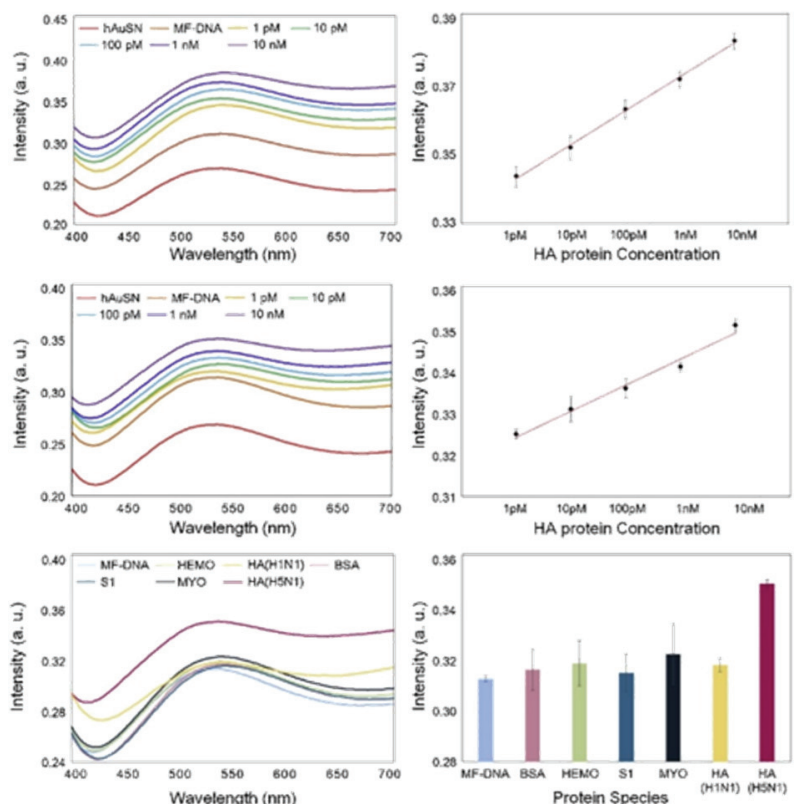

Figure 5. (A) Schematic illustration of biosensor based on LSPR method. (B) Schematic diagram of DNA 3 WJ and TBM PAGE gel result of DNA 3 WJ, HA protein, and spike protein. (C) Detection of HA protein in PBS buffer and chicken serum and selectivity test (Reproduced with permission from [102], published by Elsevier, 2019).

A

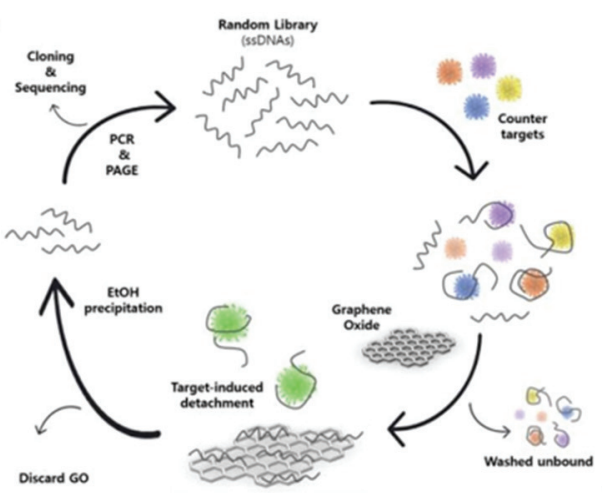

$\mathrm{B}$
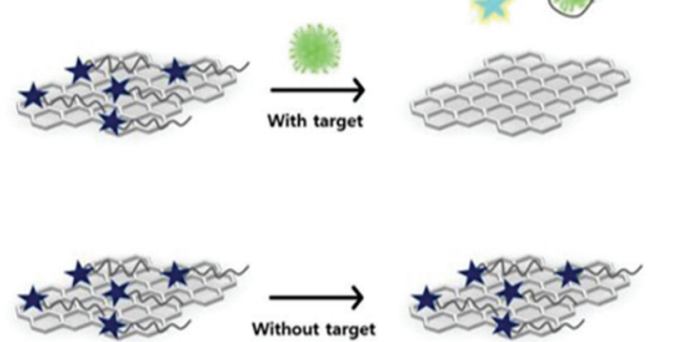

$\mathrm{C}$
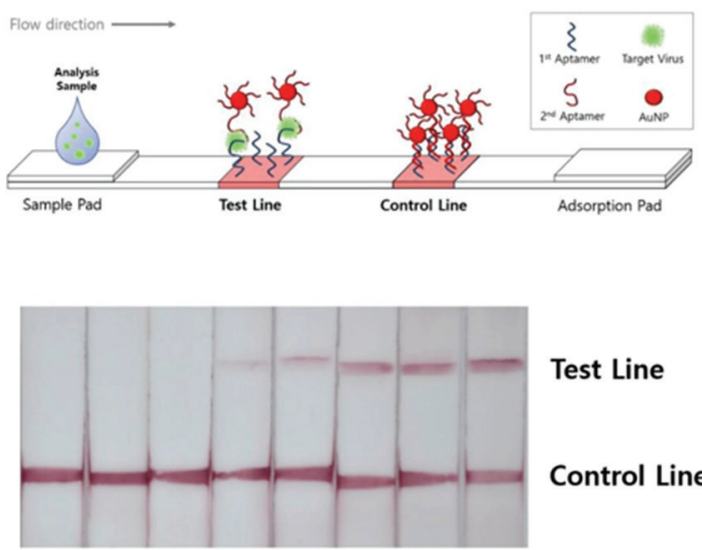

Test Line

Control Line

$\mathrm{D}$

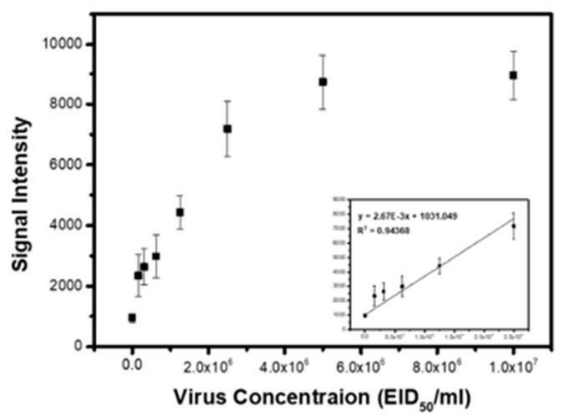

Figure 6. (A) Diagram of the immobilization-free GO-SELEX. (B) Diagram of the GO-FRET assays for aptamer characterization. (C) Diagram of whole virus particle detection system and image of the lateral flow strip. (D) Calibration curve of the cognate pair of aptamer-based sandwich-type LFAs (Reproduced with permission from [103], published by Elsevier, 2019). 
Table 3. The optical biosensing techniques discussed in this review.

\begin{tabular}{|c|c|c|c|c|}
\hline Bioprobe & Detection Method & Detection Limit & Target & Ref \\
\hline Aptamer & fluorescence & $0.4 \mathrm{HAU}$ & H5N1 & {$[75]$} \\
\hline Aptamer & Metal enhanced fluorescence & $3.5 \mathrm{ng} / \mathrm{mL}$ & H5N1 & [76] \\
\hline Aptamer & LSPR & $1 \mathrm{pM}$ & H5N1 & {$[78]$} \\
\hline Aptamer & lateral flow strip & $1.27 \times 10^{5} \mathrm{EID} 50 / \mathrm{ml}$ & $\mathrm{H} 5 \mathrm{~N} 2$ & [79] \\
\hline Aptamer & SERS & $10^{-4}$ hemagglutinin units per probe & $\mathrm{H} 3 \mathrm{~N} 2$ & [81] \\
\hline
\end{tabular}

$\mathrm{EID}_{50} / \mathrm{ml}$ ) of the target virus. Using two aptamers capable of binding to one target at the same time has the advantage that sensitive detection using aptamer labels is possible without labeling the target molecule. In particular, oligonucleotides are useful for being used as secondary binding probes because they are easy to synthesize and modify. The range of $6 \times 10^{5}-1 \times 10^{7}$ $\mathrm{EID}_{50} / \mathrm{ml}$ can be detected by the naked eye, and the detection limit was estimated to be $1.27 \times 10^{5} \mathrm{EID}_{50} / \mathrm{ml}$ through the calibration plot shown in Figure 6(D).

Raman spectroscopy is a very attractive tool for biosensor applications because it can confirm the composition and structure of biomaterials at the molecular level ${ }^{80}$. In addition, due to the multi-peak, it is possible to detect multiple components with high sensitivity, and only a few samples are used. However, the disadvantage is that the signal strength is very weak. Metal nanoparticles were introduced to overcome this disadvantage. It has been found that Raman signals are enhanced by metal nanoparticles that cause plasmon resonance, and biosensors that have introduced them are being studied.

Kukushkin's group conducted a sandwich SERS assay using two different aptamers with high sensitivity for $\mathrm{HA}^{81}$. After fixing the thiol-attached primary aptamer to $\mathrm{Ag}$ particles, the virus was bound to generate a Raman signal through a secondary aptamer bound to $\mathrm{Cy} 3$, resulting in $10^{6}-10^{9}$-fold signal amplification. The detection limit was confirmed to detect up to $10^{-4} \mathrm{HA}$ units per probe, showing that it was possible to recognize various strains of influenza virus including $\mathrm{H} 1, \mathrm{H} 3$, and $\mathrm{H} 5 \mathrm{HA}$ subtypes. Table 3 shows the optical biosensing techniques for detecting IV discussed in this review. So far, we have reviewed at methods of detection using the HA protein of IV. However, there is also a method of detecting IV using an internal protein with few mutations ${ }^{82,83}$.

\section{Future Prospective}

Historically, the outbreak of IV changed the history in the world, and notable examples include Spanish flu, Hong Kong influenza virus, swine flu, and avian influenza. Governments tried to control the social exchange in person to block the spread of IV infections by changing personal lifestyle and establishing policies affecting hygiene, sanitation, and healthcare. Furthermore, viruses with various mutations might appear again and serious impact on the human life. IV spread of various subtypes caused economic loss, a number of victims (humans and animals), and ethnic problems. As we discussed in this review, the aptamer-based electrochemical biosensor and optical biosensor can be powerful candidates for early IV diagnosis. The aptamer-based biosensor has several advantages compared to the antibody-based biosensor: 1) The aptamer can be manufactured chemically, decreasing the biosensor production time. 2) The screening speed of an aptamer against an unknown virus is faster than with an antibody. 3) It can be easily modified with chemical modification. These advantages showed the possibility of commercializing field-ready aptamer-based biosensors. However, some limitations should be attended to alter the antibody- based biosensor including low affinity between target-aptamer, less stability, selectivity, reliability, clinical sensitivity, and feasibility issues. Nevertheless, the aptamer-based biosensor is still attractive for IV detection, and it can be integrated with wearable electronics and a field-ready diagnosis system that contributes to the preventing the spread of various viruses.

Acknowledgements This research was supported by Basic Science Research Program through the National Research Foundation of Korea (NRF) funded by the Ministry of Education (2018R1D1A1B07049407) and by Korea Environment Industry \& Technology Institute(KEITI) through the program for the management of aquatic ecosystem health, funded by Korea Ministry of Environment(MOE) (2020003030001) and by the Industrial Core Technology Development Program(20009121, Development of early diagnostic system of peritoneal fibrosis by multiplex detection 
of exosomal nucleic acids and protein markers) funded by the Ministry of Trade, Industry and Energy (MOTIE, Korea)

Conflict of Interests The authors declare no competing financial interests.

\section{References}

1. Wong, A.C., Li, X., Lau, S.K. \& Woo, P.C. Global epidemiology of bat coronaviruses. Viruses 11, 174 (2019).

2. Wang, L.F., Shi, Z., Zhang, S., Field, H., Daszak, P. $\&$ Eaton, B.T. Review of bats and SARS. Emerging Infect. Dis. 12, 1834-1840 (2006).

3. Zumla, A., Hui, D.S. \& Perlman, S. Middle East respiratory syndrome. The Lancet 386, 995-1007 (2015).

4. Ye, Q., Wang, B. \& Mao, J. The pathogenesis and treatment of the Cytokine Storm in COVID-19. J. Infect. 80, 607-613 (2020).

5. Chen, N., Zhou, M., Dong, X., Qu, J., Gong, F., Han, Y., Qiu, Y., Wang, J., Liu, Y., Wei, Y., Xia, J., Yu, T., Zhang, X. \& Zhang, L. Epidemiological and clinical characteristics of 99 cases of 2019 novel coronavirus pneumonia in Wuhan, China: a descriptive study. The Lancet 395, 507-513 (2020).

6. Malone, R.W., Homan, J., Callahan, M.V., Glasspool-Malone, J., Damodaran, L., Schneider, A.D.B., Zimler, R., Talton J., Cobb, R.R., Ruzic, I., SmithGagen, J., Janies, D. \& Wilson, J. Zika Response Working Group. Zika virus: medical countermeasure development challenges. PLoS Neglected Trop. Dis. 10, e0004530 (2016).

7. Fauci, A.S. \& Morens, D.M. Zika virus in the Americas-yet another arbovirus threat. N. Engl. J. Med. 374, 601-604 (2016).

8. Van den Bruel, A., Haj-Hassan, T., Thompson, M., Buntinx, F., Mant, D. \& European Research Network on Recognising Serious Infection investigators. Diagnostic value of clinical features at presentation to identify serious infection in children in developed countries: a systematic review. The Lancet 375, 834-845 (2019).

9. Bhatt, S., Gething, P.W., Brady, O.J., Messina, J.P., Farlow, A.W., Moyes, C.L., Drake, J.M., Brownstein, J,S., Hoen, A,G., Sankoh, O., Myers, M.F., George, D,B., Jaenisch, T., Wint, G,R,W., Simmons, C,P., Scott, T,W., Farrar, J.J. \& Hay, S.I. The global distribution and burden of dengue. Nature 496, 504-507 (2013).

10. Ramanan, P., Shabman, R.S., Brown, C.S., Amarasinghe, G.K., Basler, C.F. \& Leung, D.W. Filoviral immune evasion mechanisms. Viruses 3, 1634-1649
(2011).

11. Biere, B., Bauer, B. \& Schweiger, B. Differentiation of influenza B virus lineages Yamagata and Victoria by real-time PCR. J. Clin. Microbiol. 48, 1425-1427 (2010).

12. Nobusawa, E. \& Sato, K. Comparison of the mutation rates of human influenza $\mathrm{A}$ and $\mathrm{B}$ viruses. $J$. Virol. 80, 3675-3678 (2006).

13. Noda, T. Native morphology of influenza virions. Front. Microbiol. 2, 269 (2012).

14. Nayak, D.P., Hui, E.K.W. \& Barman, S. Assembly and budding of influenza virus. Virus Res. 106, 147-165 (2004).

15. Guo, Y.J., Jin, F.G., Wang, P., Wang, M. \& Zhu, J.M. Isolation of influenza $\mathrm{C}$ virus from pigs and experimental infection of pigs with influenza $\mathrm{C}$ virus J. Gen. Virol. 64, 177-182 (1983).

16. Osterhaus, A.D.M.E., Rimmelzwaan, G.F., Martina, B.E.E., Bestebroer, T.M. \& Fouchier, R.A.M. Influenza B virus in seals. Science 288, 1051-1053 (2000).

17. Dadonaite, B., Vijayakrishnan, S., Fodor, E., Bhella, D. \& Hutchinson, E.C. Filamentous influenza viruses. J. Gen. Virol. 97, 1755-1764 (2016).

18. Dadonaite, B., Gilbertson, B., Knight, M.L., Trifkovic, S., Rockman, S., Laederach, A., Brown, L.E., Fodor, E. \& Bauer, D.L. The structure of the influenza A virus genome. Nat. Microbiol. 4, 1781-1789 (2019).

19. Fournier, E., Moules, V., Essere, B., Paillart, J.C., Sirbat, J.D., Isel, C., Cavalier, A., Rolland, J.P., Thomas, D., Lina, B. \& Marquet, R. A supramolecular assembly formed by influenza A virus genomic RNA segments. Nucleic Acids Res. 40, 2197-2209 (2012).

20. Tong, S., Zhu, X., Li, Y., Shi, M., Zhang, J., Bourgeois, M., Yang, H., Chen, X. Recuenco, S., Gomez, J, Chen, L.M., Johnson, A., Tao, Y., Dreyfus, C., Yu, W., McBride, R., Carney, P.J., Gilbert, A.T., Chang, J., Guo, Z., Davis, C.T., Paulson, J.C., Stevens, J., Rupprecht, C.E., Holmes, E,C., Wilson, I.A. \& Donis, R.O. New world bats harbor diverse influenza A viruses. PLoS Pathog. 9, e1003657 (2013).

21. Brundage, J.F. \& Shanks, G.D. What really happened during the 1918 influenza pandemic? The importance of bacterial secondary infections. J. Infect. Dis. 196, 1717-1718 (2007).

22. Biggerstaff, M., Cauchemez, S., Reed, C., Gambhir, M. \& Finelli, L. Estimates of the reproduction number for seasonal, pandemic, and zoonotic influenza: a systematic review of the literature. BMC Infect. Dis. 14, 480 (2014).

23. Myers, K.P., Olsen, C.W. \& Gray, G.C. Cases of swine influenza in humans: a review of the literature. Clin. Infect. Dis. 44, 1084-1088 (2007).

24. Abolnik, C. A current review of avian influenza in 
pigeons and doves (Columbidae). Vet. Microbiol. 170, 181-196 (2014).

25. Peaper, D.R. \& Landry, M.L. Rapid diagnosis of influenza: state of the art. Clinics in laboratory medicine 34, 365-385 (2014).

26. Verhagen, J.H., Lexmond, P., Vuong, O., Schutten, M., Guldemeester, J., Osterhaus, A.D.M.E., Elbers, A.R.W., Slaterus, R., Hornman, M., Koch, G. \& Fouchier, R.A.M. Discordant detection of avian influenza virus subtypes in time and space between poultry and wild birds; Towards improvement of surveillance programs. PloS One 12, e0173470 (2017).

27. Vemula, S.V., Zhao, J., Liu, J., Wang, X., Biswas, S. \& Hewlett, I. Current approaches for diagnosis of influenza virus infections in humans. Viruses 8, 96 (2016).

28. Dziąbowska, K., Czaczyk, E. \& Nidzworski, D. Detection methods of human and animal influenza virus - current trends. Biosensors 8, 94 (2018).

29. Zhang, H. \& Miller, B.L. Immunosensor-based label-free and multiplex detection of influenza viruses: State of the art. Biosens. Bioelectron. 141, 111476 (2019).

30. Pachucki, C.T., Khurshid, M.A. \& Nawrocki, J. Utility of reverse transcriptase PCR for rapid diagnosis of influenza a virus infection and detection of amantadine-resistant influenza a virus isolates. $J$. Clin. Microbiol. 42, 2796-2798 (2004).

31. Lee, T., Ahn, J.H., Choi, J., Lee, Y., Kim, J.M., Park, C., Jang, H., Kim, T.H. \& Lee, M.H. Development of the troponin detection system based on the nanostructure. Micromachines 10, 203 (2019).

32. Lee, T., Ahn, J.H., Park, S.Y., Kim, G.H., Kim, J., Kim, T.H., Nam, I., Park, C. \& Lee, M.H. Recent advances in AIV biosensors composed of nanobio hybrid material. Micromachines 9, 651 (2018).

33. Joyce, G.F. In vitro evolution of nucleic acids. Curr. Opin. Struct. Biol. 4, 331-336 (1994).

34. Lee, K.Y., Kang, H., Ryu, S.H., Lee, D.S., Lee, J.H. \& Kim, S. Bioimaging of nucleolin aptamer-containing 5-(N-benzylcarboxyamide)-2'-deoxyuridine more capable of specific binding to targets in cancer cells. J. Biomed. Biotechnol. 2010, 168306 (2010).

35. Villalonga, A., Pérez-Calabuig, A.M. \& Villalonga, R. Electrochemical biosensors based on nucleic acid aptamers. Anal. Bioanal. Chem.412, 55-72 (2020).

36. Ellington, A.D. \& Szostak, J.W. In vitro selection of RNA molecules that bind specific ligands. Nature 346, 818-822 (1990).

37. Jing, M. \& Bowser, M.T. Methods for measuring aptamer-protein equilibria: a review. Anal. Chim. Acta 686, 9-18 (2011).

38. Ohuchi, S. Cell-SELEX technology. BioRes. Open Access 1, 265-272 (2012).
39. Nguyen, V.T., Kwon, Y.S., Kim, J.H. \& Gu, M.B. Multiple GO-SELEX for efficient screening of flexible aptamers. Chem. Commun. 50, 10513-10516 (2014).

40. Tsae, P.K. \& DeRosa, M.C. Outlook for aptamers after twenty five years. Curr. Top. Med. Chem. (Sharjah, United Arab Emirates) 15, 1153-1159 (2015).

41. Zhu, Q., Liu, G. \& Kai, M. DNA aptamers in the diagnosis and treatment of human diseases. Molecules 20, 20979-20997 (2015).

42. Mallikaratchy, P.R., Ruggiero, A., Gardner, J.R., Kuryavyi, V., Maguire, W.F., Heaney, M.L., McDevitt, M.R., Patel, D.J. \& Scheinberg, D.A. A multivalent DNA aptamer specific for the B-cell receptor on human lymphoma and leukemia. Nucleic Acids Res. 39, 2458-2469 (2011).

43. Lakhin, A.V., Tarantul, V.Z. \& Gening, L. Aptamers: problems, solutions and prospects. Acta Naturae 5, 34-43 (2013).

44. Hori, S.I., Herrera, A., Rossi, J.J. \& Zhou, J. Current advances in aptamers for cancer diagnosis and therapy. Cancers 10, 9 (2018).

45. Yu, T., Xu, H., Zhao, Y., Han, Y., Zhang, Y., Zhang, J., Xu, C., Wang, W., Guo, Q. \& Ge, J. Aptamer based high throughput colorimetric biosensor for detection of staphylococcus aureus. Sci. Rep. 10, 9190 (2020).

46. Park, S.Y., Kim, J., Yim, G., Jang, H., Lee, Y., Kim, S.M., Park, C., Lee, M.H. \& Lee, T. Fabrication of electrochemical biosensor composed of multi-functional DNA/rhodium nanoplate heterolayer for thyroxine detection in clinical sample. Colloids Surf., B 195, 111240 (2020).

47. Lee, T., Kim, J., Nam, I., Lee, Y., Kim, H.E., Sohn, H., Kim, S.E., Yoon, J., Seo, S.W., Lee, M.H. \& Park, C. Fabrication of troponin I biosensor composed of multi-functional DNA structure/Au nanocrystal using electrochemical and localized surface plasmon resonance dual-detection method. Nanomaterials 9, 1000 (2019).

48. Lee, J.H., Oh, B.K. \& Choi, J.W. Development of a HIV-1 virus detection system based on nanotechnology. Sensors 15, 9915-9927 (2015).

49. Yang, C., Wang, Y., Ge, M.H., Fu, Y.J., Hao, R., Islam, K., Huang, P., Chen, F., Sun, J., Hong, D.F. \& Naranmandura, H. Rapid identification of specific DNA aptamers precisely targeting CD33 positive leukemia cells through a paired cell-based approach. Biomater. Sci. 7, 938-950 (2019).

50. Wildner, S., Huber, S., Regl, C., Huber, C.G., Lohrig, U., \& Gadermaier, G. Aptamers as quality control tool for production, storage and biosimilarity of the anti-CD20 biopharmaceutical rituximab. Sci. Rep. 9, 1111 (2019). 
51. van den Kieboom, C.H., van der Beek, S.L., Mészáros, T., Gyurcsányi, R.E., Ferwerda, G., \& de Jonge, M.I. Aptasensors for viral diagnostics. TrAC TrAC, Trends Anal. Chem. 74, 58-67 (2015).

52. Hassanpour, S., Baradaran, B., Hejazi, M., Hasanzadeh, M., Mokhtarzadeh, A. \& de la Guardia, M. Recent trends in rapid detection of influenza infections by bio and nanobiosensor. TrAC, Trends Anal. Chem. 98, 201-215 (2018).

53. Dong, S., Zhao, R., Zhu, J., Lu, X., Li, Y., Qiu, S., Jia, L., Jiao, X., Song, S., Fan, C., Hao, R. \& Song, H. Electrochemical DNA biosensor based on a tetrahedral nanostructure probe for the detection of avian influenza A (H7N9) virus. ACS Appl. Mater. Interfaces 7, 8834-8842 (2015).

54. Lee, T., Park, S.Y., Jang, H., Kim, G.H., Lee, Y., Park, C., Mohammadniaei, M., Lee, M,H. \& Min, J. Fabrication of electrochemical biosensor consisted of multi-functional DNA structure/porous au nanoparticle for avian influenza virus (H5N1) in chicken serum. Mater. Sci. Eng., C 99, 511-519 (2019).

55. Zelada-Guillén, G.A., Riu, J., Düzgün, A., \& Rius, F.X. Immediate detection of living bacteria at ultralow concentrations using a carbon nanotube based potentiometric aptasensor. Angew. Chem. Int. Ed. 48, 7334-7337 (2009).

56. Kiilerich-Pedersen, K., Dapra, J., Cherre, S. \& Rozlosnik, S. High sensitivity point-of-care device for direct virus diagnostics. Biosens. Bioelectron. 49, 374-379 (2013).

57. Bhardwaj, J., Chaudhary, N., Kim, H. \& Jang, J. Subtyping of influenza A H1N1 virus using a label-free electrochemical biosensor based on the DNA aptamer targeting the stem region of HA protein. Anal. Chim. Acta 1064, 94-103 (2019).

58. Pourakbari, R., Shadjou, N., Yousefi, H., Isildak, I., Yousefi, M., Rashidi, M.R. \& Khalilzadeh, B. Recent progress in nanomaterial-based electrochemical biosensors for pathogenic bacteria. Microchim. Acta 186, 820 (2019).

59. Kour, R., Arya, S., Young, S.J., Gupta, V., Bandhoria, P. \& Khosla, A. Recent Advances in Carbon Nanomaterials as Electrochemical Biosensors. Journal of The Electrochemical Society 167.3, 037555 (2020).

60. Pilehvar, S. \& De Wael, K. Recent advances in electrochemical biosensors based on fullerene-C60 nano-structured platforms. Biosensors 5, 712-735 (2015).

61. Chen, A., Sanghamitra, C. Nanomaterials based electrochemical sensors for biomedical applications. Chem. Soc. Rev. 42, 5425-5438 (2013).

62. Bai, C., Lu, Z., Jiang, H., Yang, Z., Liu, X., Ding, H., Li, H, Dong, J., Huang, A., Fang, T., Jiang, Y., Zhu, L., Lou, X., Li, S. \& Shao, N. Aptamer selection and application in multivalent binding-based electrical impedance detection of inactivated H1N1 virus. Biosens. Bioelectron. 110, 162-167 (2018).

63. Brosel-Oliu, S., Ferreira, R., Uria, N., Abramova, N., Gargallo, R., Muñoz-Pascual, F.X., \& Bratov, A. Novel impedimetric aptasensor for label-free detection of Escherichia coli O157: H7. Sens. Actuators, B 255, 2988-2995 (2018).

64. Fu, Y., Callaway, Z., Lum, J., Wang, R., Lin, J. \& Li, Y. Exploiting enzyme catalysis in ultra-low ion strength media for impedance biosensing of avian influenza virus using a bare interdigitated electrode. Anal. Chem. 86, 1965-1971 (2014).

65. Liu, X.G., Cheng, Z.Q., Fan, H., Ai, S.Y., \& Han, R.X. Electrochemical detection of avian influenza virus H5N1 gene sequence using a DNA aptamer immobilized onto a hybrid nanomaterial-modified electrode. Electrochim. Acta 56, 6266-6270 (2011).

66. Farhana Sharmin, D., Kim, S. \& Lee. H.J. Amperometric bioaffinity sensing platform for avian influenza virus proteins with aptamer modified gold nanoparticles on carbon chips. Biosens. Bioelectron. 72, 355-361 (2015).

67. Dong, S., Zhao, R., Zhu, J., Lu, X., Li, Y., Qiu, S., Jia, L., Jiao, X., Song, S., Fan, C., Hao, R. \& Song, H. Electrochemical DNA biosensor based on a tetrahedral nanostructure probe for the detection of avian influenza A (H7N9) virus. ACS Appl. Mater. Interfaces 7, 8834-8842 (2015).

68. Peltomaa, R., Glahn-Martínez, B., Benito-Peña, E. \& Moreno-Bondi, M.C. Optical biosensors for label-free detection of small molecules. Sensors $\mathbf{1 8}$, 4126 (2018).

69. Huertas, C.S., Calvo Lozano, O., Mitchell, A. \& Lechuga, L.M. Advanced evanescent-wave optical biosensors for the detection of nucleic acids: An analytic perspective. Front. Chem. 7, 724 (2019).

70. Jiang, H., Jiang, D., Shao, J., Sun, X. \& Wang, J. High-throughput living cell-based optical biosensor for detection of bacterial lipopolysaccharide (LPS) using a red fluorescent protein reporter system. Sci. Rep. 6, 36987 (2016).

71. Lu, X., Dong, X., Zhang, K., Han, X., Fang, X. \& Zhang, Y. A gold nanorods-based fluorescent biosensor for the detection of hepatitis B virus DNA based on fluorescence resonance energy transfer. Analyst 138, 642-650 (2013).

72. Mao, X., Liu, S., Yang, C., Liu, F., Wang, K. \& Chen, G. Colorimetric detection of hepatitis B virus (HBV) DNA based on DNA-templated copper nanoclusters. Anal. Chim. Acta 909, 101-108 (2016).

73. Bai, H., Wang, R., Hargis, B., Lu, H. \& Li, Y. A SPR aptasensor for detection of avian influenza virus H5N1. Sensors 12, 12506-12518 (2012).

74. Driskell, J.D., Zhu, Y., Kirkwood, C.D., Zhao, Y., Dluhy, R.A. \& Tripp, R.A. Rapid and sensitive de- 
tection of rotavirus molecular signatures using surface enhanced Raman spectroscopy. PLoS One 5, e10222 (2010).

75. Xu, L., Wang, R., Kelso, L.C., Ying, Y. \& Li, Y. A target-responsive and size-dependent hydrogel aptasensor embedded with QD fluorescent reporters for rapid detection of avian influenza virus H5N1. Sens. Actuators, B 234, 98-108 (2016).

76. Pang, Y., Rong, Z., Wang, J., Xiao, R. \& Wang, S. A fluorescent aptasensor for $\mathrm{H} 5 \mathrm{~N} 1$ influenza virus detection based-on the core-shell nanoparticles metal-enhanced fluorescence (MEF). Biosens. Bioelectron. 66, 527-532 (2015).

77. Lee, J.H. Kim, B.C., Oh, B.K. \& Choi, J.W., Highly sensitive localized surface plasmon resonance immunosensor for label-free detection of HIV-1. Nanomed. Nanotechnol. Biol. Med. 9, 1018-1026 (2013).

78. Lee, T., Kim, G.H., Kim, S.M., Hong, K., Kim, Y., Park, C., Sohn, H. \& Min, J. Label-free localized surface plasmon resonance biosensor composed of multi-functional DNA 3 way junction on hollow $\mathrm{Au}$ spike-like nanoparticles (HAuSN) for avian influenza virus detection. Colloids Surf., B 182, 110341 (2019).

79. Kim, S.H., Lee, J., Lee, B.H., Song, C.S. \& Gu,
M.B. Specific detection of avian influenza H5N2 whole virus particles on lateral flow strips using a pair of sandwich-type aptamers. Biosens. Bioelectron. 134, 123-129 (2019).

80. Alvarez-Puebla, R.A. \& Liz-Marzán, L.M. SERSbased diagnosis and biodetection. Small 6, 604-610 (2010).

81. Kukushkin, V.I., Ivanov, N.M., Novoseltseva, A.A., Gambaryan, A.S., Yaminsky, I.V., Kopylov, A.M. \& Zavyalova, E.G. Highly sensitive detection of influenza virus with SERS aptasensor. PLoS One 14, e0216247 (2019).

82. Lee, I., Kim, S.E., Lee, J., Woo, D.H., Lee, S., Pyo, H., Song, C.S. \& Lee, J. A self-calibrating electrochemical aptasensing platform: Correcting external interference errors for the reliable and stable detection of avian influenza viruses. Biosens. Bioelectron. 152, 112010 (2020).

83. Kim, J., Kwon, J.H., Jang, J., Lee, H., Kim, S., Hahn, Y.K., Kim, S.K., Lee, K.H., Lee, S., Pyo, H., Song, C.S. \& Lee, J. Rapid and background-free detection of avian influenza virus in opaque sample using NIR-to-NIR upconversion nanoparticle-based lateral flow immunoassay platform. Biosens. Bioelectron. 112, 209-215 (2018).

Copyright for the published papers belongs to the Korean BioChip Society. pISSN 1976-0280. eISSN 2092-7843. 